\title{
TEMPERATURE AND ITS VARIATIONS IN BIRTH RATES AND SEX RATIO IN GREATER YOLA, NIGERIA
}

AMBROSE A. ZEMBA

\author{
(Received 14 November 2002; Revision Accepted 23 July 2003)
}

\section{ABSTRACT}

The relationship between birth rates, sex ratio and temperature in Yola has been investigated. Data on temperature and births, for 12 years (1990-2001), were collected from Federal Meteorological Department, Yola and Federal medical Centre, Yola respectively. Average mean monthly births and temperature data for the period of study were analyzed and subjected to statistical test. Also, mean monthly data, nine months before the births of the children whose birth records were used for this study, were computed for three years. The Mean monthly birth records and their corresponding temperature values, for the 3 years, were subjected to correlation statistical test to find out the relationship between them. The results have shown that there is negative relationship between birth rates and temperature. That is, rates of conceptions among women generally, increase during relatively low temperature periods and vice versa. While female birth rates are negatively related with temperature, the reverse is the case with male births. This implies that the ratio of female birth decreases with increasing temperature whereas male births increase when temperature is higher. The paper finally emphasizes the need to minimize the effects of high temperature in our living environments by way of ensuring adequate circulation of air.

KEYWORDS: $\quad$ Temperature, Conception, Birth rate, Population, Sex ratio.

\section{INTRODUCTION}

The fact that climatic elements, particularly temperature, significantly influence human health and physiology is indisputable. This is why Ayoade (1983), clearly asserted that human health and physiology are affected more by climate than any other elements of the physical environment. Climate does not only affect the external structure of man but regulates internal activities like the rate of metabolism, glandular activities, blood sugar levels, viability of garmetes and chromosomes etc. Based on the research findings of various scholars, it can now with certainty be said that birth rates and sex ratios vary with seasons. For instance, Miura (1987) reported that, in Europe, the peak period is in spring while it is in fall or autumn in America. For the tropical Africa, Takahashi (1972) noted that the rates peak in summer (April to June) with slight variations from one area to another. Rehan's (1982) findings indicate a rather high sex ratio for Hausa land of northern Nigeria where he discovered a ratio of $1: 1.07$ on average compared to the usually accepted value of 1:1.04 for populations of African origins. Similarly, Ayeni (in Odumosu, 1991) reported a sex ratio of $1: 1.05$ in a survey of 315,735 births recorded in Lagos and its adjoining villages. He also recorded a sex ratio of 1:1.06 among 548,558 hospital births in the same localities.

In noting the effects of temperatures on sex ratio, Takahashi (1972), maintained that areas with high range of temperature seemed to respond positively to sex ratio than areas with small range. However, it is also important to note that some other factors, which influence sex ratios, are in one way or the other dependent on temperature. To Takahashi, when temperature rises beyond $300 \mathrm{C}$, it leads to loss of vitality in man that in turn leads to low male birth ratio. This implies that when there is high temperature, there is the tendency for the garmetes carrying male chromosomes to die first since it cannot swim in high temperature hazard environment.

The significance of temperature hazard probably makes it necessary to study sex ratios, particularly in relation to temperature variations. In this paper, an investigation is carried out to examine some relationships between birth rates and temperature as well as sex ratio and temperature in Yola, where Zemba (2002) reported a maximum urban temperature value of $46.80 \mathrm{C}$ within the city in April.

\section{Description of the Study Area}

The study area comprises Yola North, and parts of Yola South and Girei Local Government Areas, collectively known as Greater Yola (Fig.1). These are the immediate catchment areas for the sources of data used for this study. The study area is located between latitude $9007 \mathrm{~N}$ and $9023^{\prime} \mathrm{N}$ and longitude $12017^{\prime} \mathrm{E}$ and $12023^{\circ} \mathrm{E}$. It falls within the tropical savanna climate with distinct dry and wet seasons. Dry season lasts for about six months (November to April) while the rainy season spans from May to October. The temperature of the area is high throughout the year with a maximum of about $430 \mathrm{C}$ around March/April. Generally, there is a gradual increase in temperature from January to April. There is a distinct drop in temperature at the onset of rains. A slight increase after the cessation of rains is common before the 
onset of harmattan in December when the temperature drops further.

The population of the area according to 1991 census stood at 255,338 with a male ratio of $51.5 \%$. With a growth rate of $2.83 \%$ this population was projected to be 340,867 in 2001. Nwagboso and Uyanga, in Adebayo and Tukur 1999, have reported that male-female ratio of Adamawa State as a whole now stands at $49.9 \%$ and $50.1 \%$ respectively. This change would have affected the study area as well leading to high female ratio.

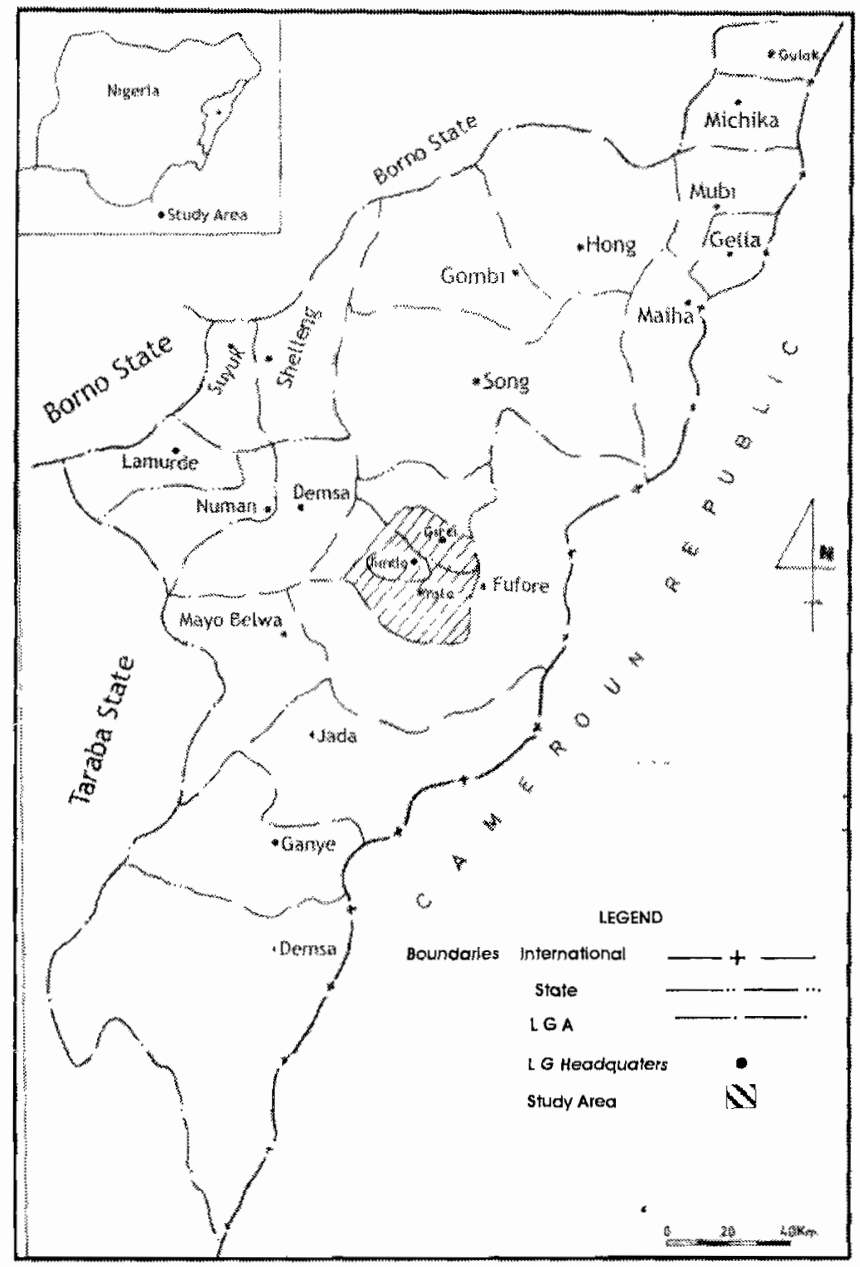

Fig 1: Map of Adamawa State Showing the Study Area Source: Adamawa State in Maps 1999.

\section{MATERIALS AND METHODS}

Data on notified births and temperature, for the period 1990-2001, were obtained from Federal Medical Centre, Yola and Federal Department of Meteorological Services, Yola, respectively, all of which are based in Jimeta city. Sex ratios were obtained from the births records. Data on births exclude women coming from outside the study area to patronize the Federal Medical Centre, Yola. In order to carry out an in-depth study of the characteristics of this population as it relates to temperature, three years (1999-
2001) data were used. In an effort to look at the relationships between birth rates and temperature, average monthiy births and temperature for the three years were found and correlated. On the other hand, to establish a relationship between sex ratio and temperature, average monthly temperature data, nine months before the births of children whose records were used for this study was calculated. This result is then matched with sex ratio to enable us see at a glance the relationship between them. For instance, births in January were conceived, under normal condition, in May $(9$ months back) the previous year. This enabled the researcher to know the conditions at the time of conception. Correlation coefficient was also used to test the relationship between temperature and sex ratio.

\section{RESULTSAND DISCUSSION}

\section{Temperature and Birth Rates}

The temperature of Yola is typical of tropical type, with average monthly values ranging from $220 \mathrm{C}$ in January to $350 \mathrm{C}$ in April. The monthly birth rate has also been observed to be highly variable, swinging between 1,830 and 5,050 during the period of study (Table 1). The data indicate a gradual fall in the rate of births from 1990 to 2001. This could be as a result of increased awareness on the need for child spacing and family planning. There is a sharp drop in births in 1996, which may perhaps be as a result of misplacement of records. The rate of female births predominates throughout the study period except in 1991, 1992 and 2001. This

conflicts with the high female population of the state by 1991 population census figure. It however suggests a reversion in the trend of sex ratio of the area. The results of statistical test indicate that there is significant negative correlation between temperature and birth rates. That is to say, the rate of conception among women tends to be low during high temperature. Specifically, this result shows that the rate of female births tends to be high during low temperature white male births are relatively high during high temperature and vice versa. This is contrary to that of Odumosu (1991). Female and male births used here refer to giving birth to female and male children respectively. Generally, the total birth rates tend to be high during low temperature. On the other hand, conceptions that eventually lead to live births occur most during low temperature periods. Hence, the fact that when the temperature is high, there is a tendency for the garmetes carrying the chromosomes to die first, since it cannot swim in the high temperature hazard environment, seems to be applicable here.

Generally, births in the area peaked in the months of May and September, in which case their possible months of conception correspond with September and January respectively. On the other hand, average minimum births are recorded in February, November and December, whose 
Table 1: Notified Births in Federal Medical Centre, Yola

$(1990-2001)$
\begin{tabular}{|c|c|l|l|l|}
\hline Year & Male & Female & Total & \% Male Sex Ratio \\
\hline 1990 & 2,470 & 2,580 & 5,050 & 48.91 \\
1991 & 2,567 & 2,359 & 4,926 & 52.11 \\
1992 & 2,249 & 1,990 & 4,239 & 53.05 \\
1993 & 1,907 & 1,959 & 3,860 & 49.33 \\
1994 & 1,835 & 1,837 & 3,672 & 49.97 \\
1995 & 1,428 & 1,452 & 2,880 & 49.58 \\
1996 & 884 & 946 & 1,830 & 48.31 \\
1997 & 1,232 & 1,540 & 2,772 & 44.44 \\
1998 & 1,109 & 1,447 & 2,556 & 43.39 \\
1999 & 1,405 & 1,544 & 2,949 & 47.64 \\
2000 & 1,350 & 1,574 & 2,924 & 46.17 \\
2001 & 1,569 & 1,389 & 2,958 & 53.66 \\
\hline Total & 2,0005 & 2,0617 & 4,0622 & 49.25 \\
\hline
\end{tabular}

Table 2: \% Sex Variations in Monthly Recorded Births in Federal Medical Centre, Yola (1999-2001)

\begin{tabular}{|c|c|c|c|c|c|c|}
\hline & \multicolumn{2}{|r|}{1999} & \multicolumn{2}{|r|}{2000} & \multicolumn{2}{|r|}{2001} \\
\hline Month & Male & Female & Male & Female & Male & Female \\
\hline January & 47.6 & 52.4 & 33.7 & 66.3 & 42.1 & 57.9 \\
\hline February & 56.4 & 43.6 & 43.2 & 56.8 & 38.5 & 61.5 \\
\hline March & 54.9 & 45.1 & 50.4 & 49.6 & 55.8 & 44.2 \\
\hline April & 40.8 & 59.2 & 44.9 & 55.1 & 55.9 & 44.1 \\
\hline May & 47.8 & 52.2 & 42.6 & 57.4 & 51.4 & 48.6 \\
\hline June & 40.7 & 59.3 & 47.8 & 52.2 & 47.2 & 52.8 \\
\hline July & 52.2 & 47.8 & 44.8 & 55.2 & 43.0 & 57.0 \\
\hline August & 56.1 & 43.9 & 51.4 & 48.6 & 58.1 & 41.9 \\
\hline September & 35.9 & 64.1 & 46.8 & 53.2 & 57.0 & 43.0 \\
\hline October & 37.5 & 62.5 & 52.2 & 47.8 & 50.9 & 49.1 \\
\hline November & 55.4 & 44.6 & 55.5 & 44.5 & 74.9 & 25.1 \\
\hline December & 57.9 & 42.1 & 58.9 & 41.1 & 53.6 & 46.4 \\
\hline
\end{tabular}

conception periods correspond with June, March and April respectively.

\section{Temperature and Sex ratio}

The percentage sex ratio of notified births for 1999 2001 is presented in Table 2 . Like birth rate, the trend of sex ratio fluctuates with seasons. Generally, the average sex ratio of the study area was found to be 1:1.03 in respect of male/female. This value is very close to the ideal or, as Odumosu (1991) puts it, accepted value of 1:1.04 for populations of African origins. Female birth ratio was consistently higher in the months of January and June throughout the three years in consideration. It was also higher for two years in the months of February, April, May, July and September. On the other hand, male ratio topped consistently in March, August, November and December. In a nutshell, therefore, female ratio is generally higher than that of male. This high female ratio is consistent with the observation of Takahashi (1972) and Rehan (1982) in India and Nigeria respectively. It confirms the fact that Africa, generally, has high female sex ratio, which is as a result of high male mortality.

To be able to find out the relationship between sex ratio and temperature, the average monthly temperature for the three years under study was computed. The result was matched with the sex ratios of Table 2, taking the male sex only. Table 3 shows how sex ratio of each month in a year was matched with the temperatures of corresponding
Table 3: Births Distribution \& Temperature for the

Corresponding Periods of Possible Conception in Yola

\begin{tabular}{|l|l|l|}
\hline \multicolumn{1}{c|}{ Variables Tested } & r-value & Remarks \\
\hline $\begin{array}{l}\text { Average birth rates 1999-2001 } \\
\text { and Temperature }\end{array}$ & -0.690 & Significant at 5\% \\
\hline 1999 Sex ratio and Temperature & 0.502 & Significant at 5\% \\
\hline 2000 Sex ratio and Temperature & 0.188 & Significant at 10\% \\
\hline 2001 Sex ratio and Temperature & 0.169 & Significant at 10\% \\
\hline
\end{tabular}

Table 4: Summary of Correlation Coefficient Results

\begin{tabular}{|c|c|c|c|c|c|c|}
\hline \multirow{2}{*}{ Month } & \multicolumn{2}{|c|}{1999} & \multicolumn{2}{|c|}{2000} & \multicolumn{2}{|r|}{2001} \\
\hline & $\begin{array}{l}\text { \%eMale } \\
\text { births }\end{array}$ & $\begin{array}{l}\text { Temp }{ }^{\circ} \mathrm{C} \\
(1998-1999)\end{array}$ & $\begin{array}{l}\text { FMale } \\
\text { births }\end{array}$ & $\begin{array}{l}\text { Temp }{ }^{6} \mathrm{C} \\
\text { (1999-2000) }\end{array}$ & $\begin{array}{l}\text { \%ole } \\
\text { births }\end{array}$ & $\begin{array}{l}\text { Temp C } \\
(2000-2001)\end{array}$ \\
\hline Jan. & 47.6 & 32.3 May 98 & 33.7 & 31.8 May 99 & 42.1 & 31.8 May 00 \\
\hline Feb. & 56.4 & 30.0 Jun ' 98 & 43.2 & 29.9 Jun 99 & 38.5 & $27.8 \operatorname{sun} 00$ \\
\hline Mar. & 54.9 & 28.0 Jul 98 & 50.4 & 27.9 Jul ' 99 & 55.8 & 27.5 Jut '00 \\
\hline April & 40.8 & 27.0 Aug 98 & 44.9 & 27.1 Aug '99 & 55.9 & 26.8 Aug '00 \\
\hline May & 47.8 & $27.3 \operatorname{Sep} 98$ & 42.6 & 26.6 Sep ' 99 & 51.4 & 27.6 Sep 00 \\
\hline June & 40.7 & 28.5 Oct 98 & 47.8 & 27.6 Oct '99 & 47.2 & 27.5 oct 100 \\
\hline July & 52.2 & 28.4 Nov 98 & 44.8 & 28.1 Nov 99 & 43.0 & 28.0 Nov 00 \\
\hline Aug. & 56.1 & 26.5 Dec 98 & 51.4 & $25.6 \mathrm{Dec}^{\prime} 99$ & 58.1 & $25.4 \mathrm{Dec}$ o0 \\
\hline Sept. & 35.9 & $21.8 \operatorname{Jan} 199$ & 56.8 & $27.5 \mathrm{Jan}$ '00 & 57.0 & $25.1 \mathrm{Jan} \cdot 01$ \\
\hline Oct. & 37.5 & 30.6 Feb ' 99 & 52.2 & $27.5 \mathrm{Feb}$ '00 & 50.9 & 27.7 Feb 01 \\
\hline Nov. & 55.4 & 33.5 Mar '99 & 55.2 & 31.7 Mar 00 & 74.9 & $32.8 \mathrm{Mar} 01$ \\
\hline Dec. & 57.9 & 34.5 Apr '99 & 58.9 & 34.2 Apr '00 & 53.6 & 33.0 Apr 01 \\
\hline
\end{tabular}

months of their conception. This enables us to see at a glance the relationship between them. The values of correlation technique suggest that there may be significant relationships between temperature and sex ratios after all. The values of correlation coefficient $(r$ ) in Table 4 could be interpreted to mean that male sex ratio increases when the temperature is higher, whereas the female sex increases during lower temperature values. This finding disagrees with that of Odumosu (1991), which is the reverse of this case. The higher female sex ratio during relatively cooler seasons could be one of the reasons why female ratios tend to be higher in the area. This is because there are generally fewer months with temperature values of above $300 \mathrm{C}$, which according to Takahashi (1972) can lead to loss of vitality in man which in turn leads to low female ratio.

\section{CONCLUSION}

It has been discovered that temperature plays a part in the variations in birth rates and sex ratios in Yola. The results obtained suggest that human reproduction responds to temperature changes. Whereas female births increase with decreasing temperature, male births tend to go up during high temperature. Generally, birth rates in the area decrease with increasing temperature. Efforts should therefore, be made to minimize the effects of high temperatures in our environments by ensuring free circulation of air so as to reduce its effects on human physiology. Efforts should also be directed towards monitoring necessary data for improvement 
in the outcome of the present research. Such data may include temperature and components of the energy balance of man that can be used for determining the thermal comfort in the atmospheric environment.

ACKNOWLEDGEMENT: The author acknowtedges Mal. Hussaini Hamidu of the Federal Medical Centre, Yola and Mr. Peter Ajeyoda of Federal Meteorological Department, Yola, for their cooperation during data collection.

\section{REFERENCES}

Ayoade, J. O., 1983. Introduction to Climatology for the Tropics, John Wiley and Sons, Chishester.

Miura, T., 1987. Causes and Effects of Births Seasonality:General Consideration, Progress in Biometeorology, Vol.16, pp1-12.

Nwagboso, N. K. and Uyanga, J., 1999. Population in Adebayo, A.A. and Tukur, A.L. (1999) Adamawa State in Maps, Dept of Geography, FUTY and Paraclete Publishers, Yola-Nigeria.

Odumosu, T., 1991. The Influence of Temperature on Sex Ratio and Birth Rates in Lagos, Nigeria in Oguntoyinbo, J. S., Omotosho, B. and Ekuwen, E.E., 1991, Meteorological Hazards and Development, Kola Okanlawon Publishers Ltd, Lagos.

Rehan, N. E., 1982. Sex of Live Born Hausa Infants, Journal of Obstetrics and Gynecology, 89: 136-149.

Takahashi, S., 1972. Geographic Distribution and Seasonal Variations of Sex Ratio at Birth in India, Journal of Human Ecology and Race Hygiene, Vol.38, No. 2

Zemba, A. A., 2002. Analysis of Urban Microclimatic Characteristics of Jimeta-Yola, An Unpublished M.Sc. Thesis Submitted to Geography Dept, Federal University of Technology, Yola, Nigeria. 